University of Louisville

ThinkIR: The University of Louisville's Institutional Repository

$12-2014$

\title{
Working memory, emotion regulation, and effortful control levels in children with attention-deficit hyperactivity disorder.
}

James Rush

University of Louisville

Follow this and additional works at: https://ir.library.louisville.edu/honors

Part of the Child Psychology Commons, and the Cognitive Psychology Commons

\section{Recommended Citation}

Rush, James, "Working memory, emotion regulation, and effortful control levels in children with attentiondeficit hyperactivity disorder." (2014). College of Arts \& Sciences Senior Honors Theses. Paper 56.

http://doi.org/10.18297/honors/56

This Senior Honors Thesis is brought to you for free and open access by the College of Arts \& Sciences at ThinkIR: The University of Louisville's Institutional Repository. It has been accepted for inclusion in College of Arts \& Sciences Senior Honors Theses by an authorized administrator of ThinkIR: The University of Louisville's Institutional Repository. This title appears here courtesy of the author, who has retained all other copyrights. For more information, please contact thinkir@louisville.edu. 
Working Memory, Emotion Regulation, and Effortful Control Levels In Children With AttentionDeficit Hyperactivity Disorder

\author{
By \\ James Rush \\ Submitted in partial fulfillment of the requirements \\ for Graduation Summa Cum Laude \\ and
}

for Graduation with Honors from the Department of Psychological and Brain Sciences

University of Louisville

December, 2014 


\begin{abstract}
ADHD
According to the Center for Disease Control (CDC), 8.4\% of American children (between the ages of 3 and 17) have been diagnosed with Attention Deficit Hyperactivity Disorder (ADHD) in 2011 alone (CDC, 2012). That approximates to 5.2 million children. ADHD is not only relatively common in children, it is also a very socially and academically debilitating disorder. ADHD is defined by the DSM-IV as having six or more symptoms from either a hyperactivity subset or an inattentive subset.

The symptoms are divided between the two subsets. Hyperactive symptoms include fidgeting or squirming, talking nonstop, or moving around quickly and erratically. Inattentive symptoms include getting easily distracted, missing details, or forgetting things. There are three different classifications of ADHD: Predominantly Hyperactive, Predominately Inattentive, or Combined (meaning there are six or more symptoms present from both subsets) (Attention Deficit Hyperactive Disorder, n.d.).
\end{abstract}

\title{
ADHD Impairment
}

Children with ADHD often experience significant academic (Scholtens, Rydell, \& Yang- Wallentin, 2013), behavioral (Becker, Luebbe, Stoppelbein, Greening, \& Fite, 2012), and social (Staikova, Gomes, Tartter, McCabe, \& Halperin, 2013) ramifications. In the academic domain, children with ADHD often have a lower sense of achievement and competence than children without ADHD (Scholtens, Rydell, \& Yang- Wallentin, 2013). This mindset combined with an inability to direct attention properly (Silva et al., 2013) leads to poorer academic performance (Daley, \& Birchwood, 2010). It is also common for children with ADHD to have poorer problem solving abilities $\left({ }^{1}\right.$ Barkley, 2006).

For more specific examples, it has been found that children with ADHD tend to be more affected by distractions in a learning environment (Adams, Finn, Moes, Flannery, \& Rizzo, 2009). The inability to block distractions affects a child's academic progress. Similarly, children diagnosed with the Inattentive subset of ADHD (ADHD-I) often have difficulties with reading, language comprehension, 
math, and academics in general (Andersen, Egeland, \& Øie, 2013). Similar findings have been observed with the Combined subset of ADHD (ADHD-C) as many of the same symptoms and deficits were found (Lemiere et al., 2010). This could be attributed to the lack of attention on the task given to them. It could also be attributed to the inability to direct attention accurately.

Behaviorally, many children with ADHD have been reported as disruptive (Zisser, \& Eyberg, 2012) and aggressive (Becker et al., 2012). Parents often state that it is difficult to raise children with ADHD and that they experience significantly more stress than parents of non-ADHD children (Steijn, Oerlemans, Aken, Buitelaar, \& Rommelse, 2013). Parental stress is potentially caused by the aggressive and disruptive nature of some children with ADHD. Many peers are also distanced from children with ADHD due to abnormal behavior. This leads to children with ADHD forming fewer friendships (Mrug, Hoza, \& Gerdes, 2001). Social situations, problem solving, and emotional control require active thought and information manipulation. If a child cannot accurately manipulate information from the environment in his/her mind, then he/she probably would have a difficult time reacting to the environment. One of the key components of being able to accomplish this manipulation is a construct known as Working Memory.

\section{Working Memory}

Working Memory (WM) refers to the ability to temporarily store and manipulate information necessary for complex processes such as learning, language comprehension, and reasoning (Baddeley, 1992). This construct is sometimes used synonymously with Short-Term Memory. However, these constructs are two separate entities. The distinction between WM and Short-Term Memory is that WM is associated more with problem solving and the active manipulation of information while Short-Term Memory is associated more with memory formation (Cowan, 2008; Baddeley, 1986).

Working memory as a whole is comprised of three components. The first of which is known as the Central Executive (CE). According to Baddeley, the CE can be thought of as the "decision maker" 
of the memory model. Specifically, the CE directs an individual's attention. The other two components of WM are sub-components of the CE. One is known as the Articulatory Loop (also known as the Phonological Loop). This manages the storage and recall of language oriented memory. The second component of the CE is the Visuospatial Sketchpad (also known as the Visuospatial Scratchpad), which manages all forms of visual information and the manipulation and storage of it (Baddeley, 1992).

Working memory uses a combination of the Visuospatial Sketchpad and the Auditory Loop to understand information in the environment. An everyday example of how the mind achieves this is when giving directions. The Visuospatial Sketchpad will visually represent the route in conscious thought. Streets and landmarks will be visible while planning the route. However, this does not portray the route for anybody else. This requires the information to be translated for the Auditory Loop. While in the Auditory Loop, the directions can be given vocally.

\section{Working Memory Impairment}

Individuals who have a lower baseline level of WM have been found to have lower academic attainment (Alloway, Gathercole, \& Elliott, 2010) and poorer social skills (Kofler et al., 2011) than individuals with a normal baseline level of WM. WM is integral to a large range of domains, including learning and problem-solving. In particular, the inability to manipulate multiple sources of information can cause issues while solving mathematical or computational problems (Ashcraft \& Krause, 2007). A classic example is attempting to solve an addition problem without the use of a pen and paper. Manipulation and storage of the numbers is essential when they cannot be written down. It is also essential to actively plan what needs to be completed next. If either of these steps do not occur (or are completed incorrectly) the problem will be unsolved.

Deficits in WM also lead to multiple problem-solving issues. The first would be that individuals with lower working memory cannot focus on particular stimuli for extended periods of time. Essentially, it means they can become easily distracted (Ahmed \& Fockert, 2012). This is impairing as 
many problems require multiple steps to solve. As an example, imagine that a child has homework due. The steps to solving this problem would be to learn the material and to consequently complete the homework before the due date. However, if WM is impaired, these two steps could be interrupted. These pauses could lead to loss of information (forgetting) or a failure to solve the problem in a timely fashion. If an individual cannot focus long enough to get through all of the steps, the problem could possibly go unsolved.

Aside from distractions or lack of attention, it has been found that lower WM is associated with difficulty learning new tasks or following directions (Alloway, Gathercole, Kirkwood, \& Elliott, 2009). For example, a recent study suggests WM and direction-following are directly linked, as younger children (with lower WM) are worse at following directions than older subjects (Engle, Carullo, \& Collins, 1991). If a child were experiencing developmental issues, it would follow that WM levels would be lower.

These children would then experience an inability to complete these tasks in a reasonable time. Children who have lower WM experience impairment in their school life and home life because of their tardiness, inability to follow directions, or difficulty with attempting new tasks. This is due to a slower processing speed among children with poorer WM (Fry \& Hale, 2000). Another issue is that children with poorer WM have difficulties manipulating information in their mind. Aside from this being an issue while solving computational problems, it can also be an issue while planning or evaluating decisions. It has been found that WM and decision making both decline with age which may suggest a relationship between the two (Del Missier et al., 2013). Lastly, WM is associated with storage of information for a short time. When WM is lower, the rate at which an individual forgets concepts drastically increases (Jonides, Lacey, \& Nee, 2005).

Similarly, lower WM can also cause issues while interpreting facial features or vocal tones of others. As discussed earlier, children with poorer WM often have difficulties with attention (Ahmed \& 
Fockert, 2012). This lack of attention can harm children in social situations. The less visual attention exhibited the more difficult it is to interpret facial expressions (Birmingham et al., 2013). This would lead to a misinterpretation of emotions, which would also lead to awkward or unsure social behavior. It has been found that children with a higher level of WM are rated as more socially competent, less aggressive, and less rejected by peers (McQuade, Murray-Close, Shoulberg, \& Hoza, 2013). In addition, a person with a low level of WM might be oblivious if they were presenting themselves in a socially unacceptable way. This is because it is difficult for them to focus on all of the features of a social situation initially, and they would not pick up on cues that an average person might. Children who randomly vocalize whatever is on their mind at the time is an example of this. If a child with average levels of WM act inappropriately, they can notice certain social cues and modify their behavior the next time. However, if WM is impaired the social cues will go unnoticed.

\section{ADHD and Working Memory}

All of the above impairments can be seen in children (and adults) diagnosed with ADHD. Observing the relationship between ADHD and WM, it can be noted that if an individual is diagnosed with ADHD they will usually have a lower score across numerous tests assessing WM including the digit forward, digit backward, Corsi block, and 2-back tests (Yang, Li, Yang, Peng, \& Ye, 2012). One of the reasons for this is differing brain physiology and responses between ADHD and non-ADHD individuals. An example is that individuals with ADHD tend to exhibit hypoactivity in certain brain areas like the Parietal and Temporal lobes when engaging in WM tasks (Fassbender et al., 2011).

Common symptoms of ADHD include an inability to focus, awkward/inappropriate social behavior, and difficulty with computational or complex tasks. Of these symptoms, most can be linked to lower WM. The impairments associated with lower levels of WM also look similar in nature to symptoms in ADHD. Like ADHD, low WM impairs individuals in the academic and social areas. One of the more important areas of impairment is poor emotional control and stability. This can be 
considered a construct of its own known as Emotion Regulation.

\section{Emotion Regulation}

Emotion Regulation (ER) refers to the process of adapting and transitioning between physiological, behavioral, and subjective emotional responses due to external or internal factors (Cole, Martin, \& Dennis, 2004). This definition implies that ER is a multifaceted construct consisting of emotional, neurological, and behavioral aspects (Hessler \& Katz, 2007). Emotions by themselves are not a harmful construct and are considered to be beneficial for social encounters and in the presence of dangerous stimuli (Levenson, 1994). They become harmful when they are imbalanced or irregular. To prove this point, close to $75 \%$ of the disorders classified in the Diagnostic and Statistical Manual of Mental Disorders (DSM-IV) have emotional issues or poor emotion regulation as a symptom (American Psychiatric Association, 1994). This statistic has been left relatively untouched based on the changes made from the DSM-IV-TR to the DSM-V (American Psychological Association, 2013). Emotion dysregulation has been associated with disorders including depression and anxiety (D’Avanzato, Joormann, Siemer, \& Gotlib, 2013), PTSD (Boden et al., 2013), and ADHD (Seymour et al., 2011).

An important aspect of ER is reactivity. This reactivity is not just an emotional or mental reaction. It is also the physiological response associated with the emotion. For example, children with poor ER exhibit a irregular patterns of respiratory sinus arrhythmia (RSA) (Vasilev, Crowell, Beauchaine, Mead, \& Gatzke-Kopp, 2009). All individuals have these natural fluctuations in heart rate while breathing or exhaling. Specifically, heart rate is suppose to increase while inhaling and decrease while exhaling. However, the fluctuations in individuals with poor ER are sometimes irregular. These irregular beats have been associated with many different psychological disorders, including depression and anxiety disorders (Beauchaine, Gatzkekopp, \& Mead, 2007). These physiological reactions could influence internal mindsets. 
Emotional awareness is also a very critical aspect of ER. In particular, the ability to distinguish emotions and categorize them is important in social situations. This concept has been called affective social competence (Halberstadt, Denham, \& Dunsmore, 2001). In order to effectively decipher social situations, it requires the active thought processes associated with recognizing internal emotions and the emotions of others. After recognition of an emotion, it is still necessary to appropriately display or hide the emotion.

If an individual cannot accurately identify their emotional status, it could have a negative impact on the social bonds that individual forms. For example, research has shown that individuals with a high level of emotional awareness have a higher understanding for the emotional experiences of others (Lane \& Schwartz, 1987). This could lead to damaging responses to a friend or family member experiencing strong emotions.

It has been found that children with poor ER are more prone to exhibit aggressive or inappropriate behavior (Herts, McLaughlin, \& Hatzenbuehler, 2012). It is not that the children only have negative thoughts but it is that they experience neutral or positive stimuli in a different manner. For example, a recent study found that children with poor ER have impairment in their ability to detect the tone of a spoken sentence (Deveney, Brotman, Decker, Pine, \& Leibenluft, 2012). Instead of hearing an intended tone, children with poor ER may hear something else entirely. Misinterpretations of tone could lead to irritability or temperament issues. This kind of reactive behavior could influence social or academic interactions in a negative way. In addition to possible aggressiveness or irritability, individuals with poor ER often experience inconsistent emotions, clouded judgment or rationale, and more intense emotions (Bradley et al., 2011).

\section{Emotion Regulation and ADHD}

As previously stated, poorer ER has been associated with ADHD (Seymour et al., 2011). Teachers and parents have reported that children diagnosed with ADHD tend to exhibit "higher highs 
and lower lows" emotionally (Anastopoulos et al., 2011). Individuals with ADHD have a limited capacity for inhibiting their emotional responses. This could lead to little or no delay between experiencing an event and reacting to that event ( ${ }^{2}$ Barkley, 2006). This delay is extremely important as it allows individuals to gather information before reacting. Another way to describe this is that individuals with ADHD do not have the ability to effectively direct attention around their environment.

As discussed earlier, ER is a multisystemic construct and is not limited to mental aspects or emotion. Physiological reactions are also considered part of an emotional experience. Many children with ADHD often exhibit strong physiological states caused by emotion (Surman et al., 2011) such as crying, yelling, getting red in the face, sweating, breathing heavy, or having an increased heart rate. These physiological responses can also have social ramifications. An example would be a child with ADHD getting visibly angry with a parent in a restaurant or any other public location. Instead of having adequate time to evaluate the situation, the child will immediately react. This reactivity often results in inappropriate behavior.

One could argue that low ER is one of the largest components of maladaptive behavior in ADHD. The inability to control emotion is crippling in many aspects of society. It could lead to social judgment, academic difficulty, and possible endangerment to their well-being. For example, children with low ER have been shown to exhibit more aggressive behavior in reaction to emotional stimuli (Melnick \& Hinshaw, 2000). This reactive behavior can cause the loss of friendships, detentions in school, or fights with other children.

\section{Emotion Regulation and Working Memory}

It has been found in a recent study that improving an individual's WM will also improve their ER (Engen \& Kanske, 2013). Theoretically, this means that the opposite could be said. If an individual has a problem regulating their emotion they could potentially have a lower level of WM. One of the possible reasons for this is that WM is associated with the ability to actively manipulate information in 
the mind. It is important to evaluate all of the possible aspects in emotional situations. If there is a limited capacity (i.e., lower WM) to do so, objectively evaluating scenarios would become significantly more difficult. This would lead to a varied range of inappropriate responses emotionally. An example of this would be a child overreacting when a candy store doesn't have the exact candy they were looking for. Instead of logically thinking of alternatives ("there might be another brand") or trying to solve the problem ("maybe there is another store that carries it") they immediately react emotionally. Later in life, the child would have difficulties in their social life, their career, and their own psychological health. One construct that is closely related to ER that could explain these behaviors is Effortful Control.

\section{Effortful Control}

Effortful Control (EC) is the ability to inhibit a dominant response while performing a subdominant response. It also is associated with planning and error detection (Dennis, Hong, \& Solomon, 2010; Rothbart \& Rueda, 2005). An individual's EC level includes many control capacities including attention direction and behavior inhibition (Posner \& Rothbart, 2000). Attentional control in particular is very important. Coping strategies are used when individuals experience negative emotions. Possibly the most widely used strategy is implementing a distraction. The inability to shift attention from a disturbing or displeasing stimulus to a neutral stimulus could lead to obsessing over the negative emotions. Individuals can cope with a negative stimulus by shifting their attention away or changing the negative meaning of the stimulus.

EC is most often used to describe an individual's control over their temperament (Vohs, 2013). Individuals with normal levels of EC may have thoughts or reactions to certain stimuli but do not immediately act on them. This is because they attend to the environment and logically think about ramifications to their actions. By distracting themselves, individuals with normal levels of EC inhibit the emotional response of a stimulus. Additionally, they will not focus on the negative stimuli as 
intently as individuals with lower levels of EC.

Some research has shown that a child's temperament can affect how well they perform on WM tasks (Wolfe \& Bell, 2004). Since temperament can be linked to EC (Vohs, 2013) then WM and EC can also be linked. Both constructs are mainly focused in attention and cognitive abilities. If an individual's ability to manipulate information decreases (low WM) then the ability to decide what stimulus deserves more or less attention also decreases (low EC). As with each of the constructs individually, this can cause impairment in academic and social areas.

A more direct connection can be observed when comparing executive functioning with EC. Executive functioning refers to a construct that governs cognitive, behavioral, and attentional processes (Blair, Zelazo, \& Greenberg, 2005). Based on this definition, WM could be categorized under executive functioning. Many similarities can be observed between EC and executive functions. Both require active cognitive processing to be effective. In particular, executive attention is a component of both concepts (Rothbart, Sheese, \& Posner, 2007). It would appear that WM and EC are highly related and depend on the other to function.

There are many factors that can contribute to an individual's level of ER. These factors include attention, temperament, executive function abilities, and effortful processing abilities (Fox \& Calkins, 2003). Since it has already been established that there is a strong link between attention, temperament, and EC then it can be said that there is a link between EC and ER. If there is a lack of control over attention, then there will likely be a lack of emotional stability.

EC is theorized to be a link between all of the constructs discussed. It has been discussed how ER and WM are both incredibly important when observing individuals with ADHD. However, EC is also the bridge between ER and WM. The ability to deactivate a dominant response while encouraging a sub-dominant response is useful in problem solving and in social situations. A recent study measured executive attention and smiling in response to receiving an undesired gift (Simonds, Kieras, Rueda, \& 
Rothbart, 2007). This is a fairly common social situation that could have negative consequences if it is assessed inefficiently. The inhibition of the dominant response (to act disappointed) and the activation of the sub-dominant response (to smile and act excited) is necessary to maintain social bonds.

Similarly, EC is also necessary in correct decision making. The same inhibition of the dominant response and activation of a sub-dominant response applies when trying to solve any type of cognitive problem. Individuals with lower EC will have a much more difficult time creating more than one solution to a problem. The dominant response (one solution) overwrites the possibility of the subdominant response (a more efficient solution) to be activated.

\section{Effortful Control and ADHD}

The above description of lower EC levels is very relevant when discussing ADHD. It has been found that low levels of EC are associated with hyperactivity and inattention (Martel \& Nigg, 2006). From this finding, it would appear that EC and ADHD are correlated. This can also be observed in the deficits in individuals with ADHD. One of these deficits is selective attention (Brodeur \& Pond, 2001). The lower the EC level the more difficult it becomes to shift attention away from some emotionally charged stimuli. This could potentially be one of the reasons why children with ADHD have been described as having "higher highs and lower lows." It is true that children with ADHD have issues focusing on tasks. However, those tasks usually are not emotionally charged. Essentially, it is very hard to divert their attention after some emotional stimulus has entered their awareness. These attention issues can lead to academic, social, and behavioral ramifications. The inability to focus on tasks is obviously damaging for a child's schoolwork. However, it is also damaging when the child attempts to form social bonds. Theoretically, children who have a lower EC would also be the children who have a tendency to have difficulty using coping skills when upset. The emotionally charged situation would stay in their attention longer which would cause the negative emotions to stay for longer periods of time. 


\section{Hypothesis}

Working Memory, Effortful Control, and Emotion Regulation are all associated with one another. This has been shown through different scales, trends, and common symptoms. However, there are not abundant amounts of empirical evidence to show this within ADHD. The purpose of this study is to observe whether all these levels are lower in children with ADHD. It could then be observed if any particular construct is influenced by another. The hypothesis is that Working Memory is directly related to Effortful Control. Effortful Control is, similarly, directly related to Emotion Regulation. As Working Memory capacity decreases, Effortful Control decreases, which is related to a lower Emotion Regulation.

\section{Methods}

\section{Participants}

Fifteen $(n=15)$ elementary and middle school children were recruited from the Louisville, Kentucky area using flyers and advertisements. All fifteen (15) children were previously diagnosed with ADHD. While it was the intention to recruit children without ADHD as well, time constraints and difficulty with recruitment limited the sample size. Thirteen (13) children were male and two (2) children were female. The children's ages ranged from 7 to 10 years of age with a mean age of 8.93 years $(S D=1.52)$. Despite the small sample size, there was racial diversity among the children. Ten (10) of the children were identified as "White," three (3) of the children were identified as "AfricanAmerican/Black," and two (2) of the children were identified as "Biracial." This data was collected from the parents and not the children themselves. Approximately half of the children that participated in the study were on prescription medications to alleviate some of the symptoms of ADHD ( $n=7)$. Informed consent was obtained from both the parents and the children.

While participation in the study was entirely voluntary, there were benefits given to the participants. For completing the study, participants were awarded gift cards that could be used at any 
location that accepts credit cards. One gift card was awarded to the child and another was awarded to the parent. These gift cards were both worth \$10.00, allowing for a total compensation of \$20.00.

In addition to monetary benefits, the parents were offered a free assessment of the child's clinical ratings, as well as an assessment of the child's IQ and Achievement testing scores. These measures were compiled by the Research on ADHD and Children's Emotion Regulation Lab (RACER) research team and were presented to the parent by a Graduate Student Assistant with clinical training or by the lab director, Dr. Paul Rosen. At any point, the participants were allowed to discontinue the study if they desired to do so.

\section{Measures}

Baseline Screening Session. Both the parents and the children who volunteered to participate in the study were asked to attend a baseline session at the University of Louisville RACER lab. Parents were then asked to read and sign an informed consent form, while the children were asked to read and sign an assent form. Both the parents and the children had the forms explained to them verbally before they were asked to sign. The children were then taken to a separate room with one of the researchers to complete the WM sections of the WISC-IV (see below).

The parents were assisted in completing a diagnostic structured interview regarding the child. The interview is called the Diagnostic Interview Schedule for Children (DISC-IV; Fisher, Lucas, Sarsfield, \& Shaffer, 2006). This interview contains algorithms to generate diagnoses and is used to determine if the child meets criteria for ADHD or not. These algorithms were designed following the rules and guidelines of the American Psychiatric Association's Diagnostic and Statistical Manual, Fourth Edition (DSM-IV; American Psychiatric Association, 2000). The parents were also given a separate interview to determine the child's impairment in functioning.

Working Memory. Children completed two subtests of the Wechsler Intelligence Scale for Children, $4^{\text {th }}$ Edition (WISC-IV; Wechsler, 1999) that comprise the Working memory Index (Digit Span 
[forward and backward] and Letter-Number Sequencing). The WISC-IV provides a standardized assessment that compares a child's score with other children in that age range. This is used to assess the children's level of WM. The raw WM Index score is placed into five different ranges : "Borderline," "Low Average," "Average," "High Average," and "Superior."

Effortful Control. Parents were asked to complete the Early Adolescent Temperament Questionnaire - Revised Edition (EATQ-R; Ellis \& Rothbart, 2001). The results from this questionnaire allow us to gauge the child's temperament. As discussed earlier, EC has been linked with the ability to regulate temperament (Vohs, 2013). The EATQ-R has been used in previous studies concerning ADHD and EC (Martel \& Nigg, 2006) with significant results.

Emotion Regulation. ER was determined from various questionnaires. Most notably parents were asked to complete the Emotion Regulation Checklist (ERC; Shields \& Cicchetti, 1997). The ERC is a parent's perception of how effective the children regulate their emotions using a 4-point likert scale. Responses gathered from the ERC can be placed into one of two subsets : Emotional Negativity and Emotion Regulation Difficulties. The ERC has been used extensively to assess ER and has proven to be a reliable measurement (Shields \& Cicchetti, 1997). For the purposes of this study, we are most interested in the subset of Emotion Regulation Difficulties.

\section{Results}

Based on the limited sample size, bivariate correlation analyses were implemented to assess the relation of the three constructs. It is also important to note that the primary focus was on effect size (the size of the correlation coefficient, or $r$ values) as opposed to statistical significance ( $\mathrm{p}$ values) when determining the strength of a correlation. This is primarily due to the low power to detect statistical significance due to the limited sample size. Effect sizes of $r=.3$ or greater were considered meaningful.

When comparing the Working Memory Ordinance and the Emotion Regulation Problems subset 
of the ERC, a negative correlation can be observed, $r(13)=-.488, p=.065$. This means that as a child's Working Memory score decreases, the amount of Emotional Regulation Problems increases (and vice versa). While the nature of this study is purely exploratory and attempting to observe effect size rather than significance, it is interesting to note that this variable is close to significance. Likewise, when comparing the Emotion Regulation Problems subset of the ERC and the results of the EATQ-R (which can be used to measure a child's Effortful Control), a negative correlation can also be observed, $r(13)=$ $-.330, p=.229$. Again, this means that as a child experiences more Emotion Regulation Problems, their Effortful Control decreases. However, contrary to my hypothesis, there was no sign of a correlation between the constructs of Effortful Control and Working Memory, $r(13)=.064, p=.819$.

\section{Discussion}

The results contain both expected and unexpected results. The intention of this study was to attempt to observe the interrelation of Effortful Control between the concepts of Working Memory and Emotion Regulation. Connections can be observed between Working Memory and Emotion Regulation and between Emotion Regulation and Effortful Control. According to previously conducted research, this appears to make sense. As stated in my introduction, the connection between Working Memory and Emotion Regulation is most likely caused by a deficit in the manipulation of information. Determining "correct" emotions for various social situations often requires an intense evaluation of the situation in general. It requires to not only the active manipulation of information obtained in the present, but it requires the knowledge of how actions will effect the future as well.

The constructs of Emotion Regulation and Effortful Control appear to have a similar relationship. Effortful Control is defined as the ability to activate a sub-dominant response while inhibiting a dominant response. For a lot of children, Emotion Regulation Problems arise from an immediate reactivity (i.e., emotional response) to certain distressing stimuli. With this idea in mind, it would follow that as a child's Effortful Control level was lowered, Emotion Regulation Problems with 
occur more frequently, which is what appears to be represented by the data. The dominant response in emotional situations would be to exhibit the reactive emotion and the sub-dominant response would be to control said emotion. It is important to note that we do not have any means to determine the directionality of these correlations. We only have the means to suggest a relationship between the two. Further studies would have to be designed to determine anything more.

However, the data appears to suggest that there is little or no connection between Working Memory and Effortful Control. I have a number of theories as to why this might be. Perhaps the easiest conclusion to arrive at is that Effortful Control is a separate entity from both Working Memory and Emotion Regulation. I originally stated that Effortful Control appeared to act as a "bridge" of sorts between the other two constructs. In light of this data, perhaps one of the other constructs is the mediator. Emotion Regulation could be the connection between Effortful Control and Working Memory or vice versa. Without follow-up data and studies, it is impossible to determine the exact relationship the three constructs share.

Another possibility involves a limitation to the study. As stated in the limitations section, Spatial Working Memory was not gathered as a part of this study, despite clear evidence that it is strongly affected in children with ADHD (Martinussen, Hayden, Hogg-Johnson, \& Tannock, 2005). While this was beyond the control of the research team and myself, it had the potential to significantly impact the results.The Working Memory data that was gathered and used for analysis was only Verbal Working Memory.

However, if the assumption is made that Effortful Control is an entirely separate construct from Working Memory and Emotion Regulation, it follows that there could exist a different, unknown construct that does mediate the two. The mental abilities and aspects of ADHD have a degree of complexity that requires more than just three constructs. The "bridge" could be a number of different constructs not yet examined. Despite the question of Effortful Control's contribution to this trinity of 
constructs, there appears to be a fairly clear link between Working Memory and Emotion Regulation. A lower Working Memory appears to correlate with more Emotion Regulating problems.

\section{Limitations}

This study is not without limitations. Perhaps the most jarring issue is the lack of an adequate sample size. Despite the small size, the fact that a significant value was almost achieved should prompt future research. However, with only 15 children to observe and compare, data may significantly change when observing a wider range of children.

Another issue is that we had no effective way to control for the medication the children were on prior to and during the study. These drugs might have some lasting effect on a number of the measures considered. In particular, the Working Memory scores might differ if the children were taken off the medications. It is unknown whether this would have a meaningful impact on the results or not.

All of the children that participated in the study were previously diagnosed with ADHD. Due to time constraints and (possibly) parental interests during recruitment, this study did not include a control sample. Possessing the ability to observe the differences between children diagnosed with ADHD and children with no prior diagnoses would be extremely beneficial. It might also allow for a greater appreciation for the results as a whole.

While it was the intention to observe both Spatial Working Memory and Verbal Working Memory, only Verbal Working Memory was assessed. This is due primarily to technical difficulties and time constraints. As mentioned in the discussion section, children with ADHD have been documented to have a lower Spatial Working Memory score than Verbal (see Martinussen, Hayden, Hogg-Johnson, \& Tannock, 2005). In addition, Spatial Working Memory is linked with problem solving and active thought processes (Thomas, 2013). While tests like Letter-Number Sequencing and Forward/Backward Digit Span tests are valid methods for determining a Working Memory score, it is only valid for gathering Verbal Working Memory. 


\section{Implication on Future Research}

As an exploratory study, the results have successfully indicated the possibility of a link between Working Memory and Emotion Regulation. Likewise, a link between Emotion Regulation and Effortful Control is also suggest by the data. This may prompt a more thorough investigation into the exact relationship between these variables. This would not only help the reliability and testability of these findings, but with a larger sample size, significantly more descriptive analyses can be implemented.

The lack of a correlation with regards to Effortful Control and Working Memory can also prompt further research. In order to elimate the possibility of an error within this study, a follow-up study with a larger sample may prove insightful. Since only fifteen children provided the information, there is a possibility that the sample is not indicative of the population as a whole.

If the results of a follow-up study indicate the same lack of a relationship between Effortful Control and Working Memory, then further studies may attempt to introduce and compare different variables within ADHD. Many aspects of ADHD have not been examined by this study, including some physiological, mental, and social components. Endless amounts of research can still be conducted to arive at a detailed analysis of ADHD and how each component affects another. If an exact understanding of how children with ADHD function on a daily basis can be achieved, methods can be developed that could help the child socially, academically, and emotionally. 


\section{References}

Adams, R., Finn, P., Moes, E., Flannery, K., \& Rizzo, A. (2009). Distractibility in attention/deficit/hyperactivity disorder (ADHD): The virtual reality classroom. Child Neuropsychology, 15(2), 120-135. doi:10.1080/09297040802169077

Ahmed, L., \& de Fockert, J. W. (2012). Focusing on attention: The effects of working memory capacity and load on selective attention. Plos ONE, 7(8), doi:10.1371/journal.pone.0043101

Alloway, T. P., Gathercole, S. E., Kirkwood, H., \& Elliott, J. (2009). The cognitive and behavioral characteristics of children with low working memory. Child Development, 80(2), 606-621.

Alloway, T., Gathercole, S. E., \& Elliott, J. (2010). Examining the link between working memory behaviour and academic attainment in children with ADHD. Developmental Medicine \& Child Neurology, 52(7), 632-636. doi:10.1111/j.1469-8749.2009.03603.x

American Psychological Association (2013). Highlights of Changes from DSM-IV-TR to DSM5. American Psychiatric Publishing, n/a. Retrieved December 1, 2013, from http://www.dsm5.org/Documents/changes\%20from\%20dsm-iv-tr\%20to\%20dsm-5.pdf American Psychiatric Association (2000). Diagnostic and statistical manual of mental disorders (4th ed., text revision). Washington, DC: Author.

Anastopoulos, A. D., Smith, T. F., Garrett, M. E., Morrissey-Kane, E., Schatz, N. K., Sommer, J. L., et al. (2011). Self-Regulation Of Emotion, Functional Impairment, And Comorbidity Among Children With AD/HD. Journal of Attention Disorders, 15(7), 583-592.

Andersen, P. N., Egeland, J., \& Øie, M. (2013). Learning and memory impairments in children and adolescents with attention-deficit/hyperactivity disorder. Journal Of Learning Disabilities, 46(5), 453-460.

Ashcraft, M. H., \& Krause, J. A. (2007). Working memory, math performance, and math anxiety. 
Running head: WM, ER, AND EC LEVELS IN ADHD

Psychonomic Bulletin \& Review, 14(2), 243-248. doi:10.3758/BF03194059

Attention Deficit Hyperactivity Disorder. (n.d.). NIMH RSS. Retrieved November 21, 2013, from

http://www.nimh.nih.gov/health/publications/attention-deficit-hyperactivity-

disorder/index.shtml

Baddeley, A. (1992). Working Memory. Science, 255(5044), 556-559.

Baddeley, A. D. (1986). Working memory. Oxford [Oxfordshire]: Clarendon Press .

${ }^{1}$ Barkley, R. A. (2006). The relevance of the Still lectures to Attention-Deficit/Hyperactivity

Disorder: A Commentary. Journal Of Attention Disorders, 10(2), 137-140.

doi:10.1177/1087054706288111

${ }^{2}$ Barkley, R. A. (2006). Attention-deficit hyperactivity disorder: a handbook for diagnosis and treatment (3. ed.). New York, NY [u.a.: Guilford Press].

Beauchaine, T., Gatzkekopp, L., \& Mead, H. (2007). Polyvagal theory and developmental psychopathology: Emotion dysregulation and conduct problems from preschool to adolescence. Biological Psychology,74(2), 174-184.

Becker, S. P., Luebbe, A. M., Stoppelbein, L., Greening, L., \& Fite, P. J. (2012). Aggression among children with ADHD, anxiety, or co-occurring symptoms: Competing exacerbation and attenuation hypotheses. Journal Of Abnormal Child Psychology, 40(4), 527-542.

doi:10.1007/s 10802-011-9590-7

Birmingham, E., Meixner, T., Iarocci, G., Kanan, C., Smilek, D., \& Tanaka, J. W. (2013). The moving window technique: A window into developmental changes in attention during facial emotion recognition. Child Development, 84(4), 1407-1424. doi:10.1111/cdev.12039

Blair, C., Zelazo, P. D., \& Greenberg, M. T. (2005). The measurement of executive function in early childhood. Developmental Neuropsychology, 28(2), 561-571.

Boden, M. T., Westermann, S., McRae, K., Kuo, J., Alvarez, J. a., Kulkarni, M. R., et al. (2013). 
Running head: WM, ER, AND EC LEVELS IN ADHD

Emotion regulation and posttraumatic stress disorder: a prospective investigation. Journal of Social and Clinical Psychology, 32(3), 296-314. Retrieved December 6, 2013, from the EBSCO database.

Bradley, B., DeFife, J. A., Guarnaccia, C., Phifer, J., Fani, N., Ressler, K. J., \& Westen, D. (2011). Emotion dysregulation and negative affect: Association with psychiatric symptoms. Journal Of Clinical Psychiatry, 72(5), 685-691. doi:10.4088/JCP.10m06409blu

Brammer, W. A., \& Lee, S. S. (2012). Impairment in children with and without ADHD: Contributions from oppositional defiant disorder and callous-unemotional traits. Journal Of Attention Disorders, 16(7), 535-543. doi:10.1177/1087054711403709

Brodeur, D. A., \& Pond, M. (2001). The development of selective attention in children with Attention Deficit Hyperactivity Disorder. Journal of Abnormal Child Psychology, 29(3), 229239.

Center for Disease Control (2012). Summary Health Statistics for U.S.Children: National Health Interview Survey. Vital and Health Statistics, 254(10). Retrieved November 21, 2013, from http://www.cdc.gov/nchs/data/series/sr_10/sr10_254.pdf

Cole, P. M., Martin, S. E., \& Dennis, T. A. (2004). Emotion Regulation As A Scientific Construct: Methodological Challenges And Directions For Child Development Research. Child Development, 75(2), 317-333.

Cowan, N. (2008). What are the differences between long-term, short-term, and working memory? Progressive Brain Research, 169, 323-338. Retrieved December 1, 2013, from http://www.ncbi.nlm.nih.gov/pmc/articles/PMC2657600/pdf/nihms84208.pdf

Daley, D. D., \& Birchwood, J. J. (2010). ADHD and academic performance: Why does ADHD impact on academic performance and what can be done to support ADHD children in the classroom? Child: Care, Health And Development, 36(4), 455-464. doi:10.1111/j.1365- 
Running head: WM, ER, AND EC LEVELS IN ADHD

2214.2009.01046.x

D’Avanzato, C., Joormann, J., Siemer, M., \& Gotlib, I. H. (2013). Emotion regulation in depression and anxiety: examining diagnostic specificity and stability of strategy use. Cognitive Therapy and Research, 37(5), 968-980. Retrieved December 6, 2013, from the EBSCO database.

Dehn, M. J. (2008). Working memory and academic learning: assessment and intervention. Hoboken, N.J.: John Wiley \& Sons, Inc.

Del Missier, F., Mäntylä, T., Hansson, P., Bruine de Bruin, W., Parker, A. M., \& Nilsson, L. (2013). The multifold relationship between memory and decision making: An individual-differences study. Journal Of Experimental Psychology: Learning, Memory, And Cognition, 39(5), 1344-1364. doi:10.1037/a0032379

Dennis, T. A., Hong, M., \& Solomon, B. (2010). Do the associations between exuberance and emotion regulation depend on effortful control? International Journal of Behavioral Development, 34(5), 462-472.

Deveney, C. M., Brotman, M. A., Decker, A., Pine, D. S., \& Leibenluft, E. (2012). Affective prosody labeling in youths with bipolar disorder or severe mood dysregulation. Journal Of Child Psychology And Psychiatry, 53(3), 262-270. doi:10.1111/j.1469-7610.2011.02482.x

Ellis, L. K., \& Rothbart, M. K. (2001). Revision of the early adolescent temperament questionnaire. Poster presented at the 2001 Biennial Meeting of the Society for Research in Child Development, Minneapolis, Minnesota

Engle, R. W., Carullo, J. J., \& Collins, K. W. (1991). Individual differences in working memory for comprehension and following directions. The Journal Of Educational Research, 84(5), 253-262.

Engen, H., \& Kanske, P. (2013). How Working Memory training improves Emotion Regulation: neural efficiency, effort, and transfer effects. The Journal of Neuroscience, 33(30), 12152- 
12153.

Fassbender, C., Schweitzer, J. B., Cortes, C. R., Tagamets, M. A., Windsor, T. A., Reeves, G. M., et al. (2011). Working memory in Attention Deficit/Hyperactivity Disorder is characterized by a lack of specialization of brain function. PLOS ONE, 6(11), e27240.

Fisher, L., Lucas, C., Sarsfield, \& Shaffer (2006). Interviewer manual. Center for Disease Control. Retrieved March 30, 2014, from http://www.cdc.gov/nchs/data/nhanes/limited_access/interviewer_manual.pdf

Fox, N. A., \& Calkins, S. D. (2003). The development of self-control of emotion: intrinsic and extrinsic influences. Motivation and Emotion, 27(1), 7-26.

Fry, A. F., \& Hale, S. (2000). Relationships among processing speed, working memory, and fluid intelligence in children. Biological Psychology, 54, 1-34.

Halberstadt, A. G., Denham, S. A., \& Dunsmore, J. C. (2001). Affective social competence. Social Development, 10(1), 79-119. doi:10.1111/1467-9507.00150

Herts, K. L., McLaughlin, K. A., \& Hatzenbuehler, M. L. (2012). Emotion dysregulation as a mechanism linking stress exposure to adolescent aggressive behavior. Journal Of Abnormal Child Psychology, 40(7), 1111-1122. doi:10.1007/s10802-012-9629-4

Hessler, D. M., \& Katz, L. F. (2007). Children's emotion regulation: Self-report and physiological response to peer provocation. Developmental Psychology, 43(1), 27-38.

Jonides, J., Lacey, S. C., \& Nee, D. E. (2005). Processes of working memory in mind and brain. Current Directions in Psychological Science, 14(1), 2-5.

Kofler, M., Rapport, M., Bolden, J., Sarver, D., Raiker, J., \& Alderson, M. (2011). Working memory deficits and social problems in children with ADHD. Journal of Abnormal Child Psychology, 39(6), 805-817.

Lane, R. D., \& Schwartz, G. E. (1987). Levels of emotional awareness: A cognitive-developmental 
Running head: WM, ER, AND EC LEVELS IN ADHD

theory and its application to psychopathology. The American Journal of Psychiatry, 144, 133 143.

Lemiere, J., Wouters, H., Sterken, C., Lagae, L., Sonuga-Barke, E., \& Danckaerts, M. (2010). Are children with ADHD predominantly inattentive and combined subtypes different in terms of aspects of everyday attention? European Child \& Adolescent Psychiatry, 19(8), 679-685. doi:10.1007/s00787-010-0105-9

Levenson, R. W. (1994). Human emotion: A functional view. In P. Ekman \& R.J. Davidson (Eds.), The nature of emotion: Fundamental questions (pp. 123-126). New York: Oxford University Press.

MacDermott, S., Gullone, E., Allen, J., King, N., \& Tonge, B. (2010). The emotion regulation index for children and adolescents (ERICA): A psychometric investigation. Journal of Psychopathology and Behavioral Assessment, 32, 301-314.

Martel, M. M., \& Nigg, J. T. (2006). Child ADHD and personality/temperament traits of reactive and effortful control, resiliency, and emotionality. Journal Of Child Psychology And Psychiatry, 47(11), 1175-1183. doi:10.1111/j.1469-7610.2006.01629.x

Martinussen, R., Hayden, J., Hogg-Johnson, S., \& Tannock, R. (2005). A meta-analysis of working memory impairments in children with Attention-Deficit/Hyperactivity Disorder. Journal Of The American Academy Of Child \& Adolescent Psychiatry, 44(4), 377-384. doi:10.1097/01.chi.0000153228.72591.73

McQuade, J., Murray-Close, D., Shoulberg, E., \& Hoza, B. (2013). Working memory and social functioning in children. Journal of Experimental Child Psychology, 3(115), 422-435.

Melnick, S. M., \& Hinshaw, S. P. (2000). Emotion regulation and parenting in AD/HD and comparison boys: linkages with social behaviors and peer preference. Journal of Abnormal Child Psychology, 28(1), 73-86. 
Miyake, A., \& Shah, P. (1999). Toward unified theories of working memory: Emerging general consensus, unresolved theoretical issues, and future research directions. In A. Miyake \& P. Shah (Eds.), Models of working memory: Mechanisms of active maintenance and executive control (442-481). New York: Cambridge University Press.

Mrug, S., Hoza, B., \& Gerdes, A. C. (2001). Children with attention-deficit/hyperactivity disorder: Peer relationships and peer-oriented interventions. New Directions for Child and Adolescent Development, 91, 51-77.

Posner, M. I., \& Rothbart, M. K. (2000). Developing mechanisms of self-regulation. Development and Psychopathology, 12, 427-441.

Rothbart, M. K., \& Rueda, M. R. (2005). The development of effortful control. Developing individuality in the human brain: A tribute to Michael I. Posner, 167-188.

Rothbart, M. K., Sheese, B. E., \& Posner, M. I. (2007). Executive attention and effortful control: Linking temperament, brain networks, and genes. Child Development Perspectives, 1(1), 2-7. Scholtens, S., Rydell, A., \& Yang- Wallentin, F. (2013). ADHD symptoms, academic achievement, self- perception of academic competence and future orientation: A longitudinal study. Scandinavian Journal Of Psychology, 54(3), 205-212. doi:10.1111/sjop.12042

Seymour, K. E., Chronis-Tuscano, A., Halldorsdottir, T., Stupica, B., Owens, K., \& Sacks, T. (2011). Emotion regulation mediates the relationship between ADHD and depressive symptoms in youth. Journal of Abnormal Child Psychology, 40, 595-606.

Shields, A., \& Cicchetti, D. (1997). Emotion regulation among school-age children: The development and validation of a new criterion Q-sort scale. Developmental Psychopathology, 33 (6), 906916.

Silva, K. L., Guimarães-da-Silva, P. O., Grevet, E. H., Victor, M. M., Salgado, C. I., Vitola, E. S., \& Bau, C. D. (2013). Cognitive deficits in adults with adhd go beyond comorbidity effects. 
Running head: WM, ER, AND EC LEVELS IN ADHD

Journal Of Attention Disorders, 17(6), 483-488. doi:10.1177/1087054711434155

Simonds, J., Kieras, J. E., Rueda, M. R., \& Rothbart, M. K. (2007). Effortful control, executive attention, and emotional regulation in 7-10-year-old children. Cognitive Development, 22, 474488.

Staikova, E., Gomes, H., Tartter, V., McCabe, A., \& Halperin, J. M. (2013). Pragmatic deficits and social impairment in children with ADHD. Journal Of Child Psychology And Psychiatry, 54(12), 1275-1283. doi:10.1111/jcpp.12082

Steijn, D. J., Oerlemans, A. M., Aken, M. G., Buitelaar, J. K., \& Rommelse, N. J. (2013). The reciprocal relationship of ASD, ADHD, depressive symptoms and stress in parents of children with ASD and/or ADHD. Journal Of Autism And Developmental Disorders, doi:10.1007/s10803-013-1958-9

Surman, C. B., Biederman, J., Spencer, T., Yorks, D., Miller, C. A., Petty, C. R., et al. (2011). Deficient Emotional Self-Regulation and Adult Attention Deficit Hyperactivity Disorder: A Family Risk Analysis. The American Journal of Psychiatry, 168(6), 617-623.

Thomas, L. E. (2013). Spatial working memory is necessary for actions to guide thought. Journal Of Experimental Psychology: Learning, Memory, And Cognition, 39(6), 1974-1981. doi:10.1037/a0033089

Universal Design of College Algebra. (n.d.).Working Memory, Attention, \& Executive Function. Retrieved November 21, 2013, from http://usablealgebra.landmark.edu/instructortraining/working-memory-attention-executive-function/

Vasilev, C. A., Crowell, S. E., Beauchaine, T. P., Mead, H. K., \& Gatzke-Kopp, L. M. (2009). Correspondence between physiological and self-report measures of emotion dysregulation: A longitudinal investigation of youth with and without psychopathology. Journal Of Child Psychology And Psychiatry, 50(11), 1357-1364. doi:10.1111/j.1469-7610.2009.02172.x 
Vohs, K. D. (2013). Effortful control handbook of self-regulation, second edition: research, theory, and applications. (pp. 263-283). New York City: Guilford Publications, Incorporated.

Wechsler, D. (1999). Wechsler Abbreviated Scale of Intelligence. Psychological Corporation. San Antonio, TX.

Wolfe, C. D., \& Bell, M. A. (2004). Working memory and inhibitory control in early childhood: contributions from physiology, temperament, and language. Developmental Psychobiology, 44(1), 68-83.

Yang, B., Li, J., Yang, S., Peng, G., \& Ye, M. (2012). Working memory deficits in children with attention deficit hyperactivity disorder. Chinese Mental Health Journal, 26(1), 41-45.

Zisser, A. R., \& Eyberg, S. M. (2012). Maternal ADHD: Parent-child interactions and relations with child disruptive behavior. Child \& Family Behavior Therapy, 34(1), 33-52.

doi:10.1080/07317107.2012.654450 